\title{
Belief, Rational And Justified
}

\author{
Forthcoming, Mind \\ Robert Weston Siscoe \\ University of Arizona \\ rwsiscoe@email.arizona.edu
}

\begin{abstract}
It is clear that beliefs can be assessed both as to their justification and their rationality. What is not as clear, however, is how the rationality and justification of belief relate to one another. Stewart Cohen has stumped for the popular proposal that rationality and justification come to the same thing, that rational beliefs just are justified beliefs, supporting his view by arguing that 'justified belief' and 'rational belief' are synonymous. In this paper, I will give reason to think that Cohen's argument is spurious. I will show that 'rational' and 'justified' occupy two distinct semantic categories - 'rational' is an absolute gradable adjective and 'justified' is a relative gradable adjective - telling against the thought that 'rational belief' and 'justified belief' are synonymous. I will then argue that the burden of proof is on those who would equate rationality and justification, making the case that those who hold this prominent position face the difficulty of explaining how rationality and justification come to the same thing even though 'rational' and 'justified' are not synonymous. ${ }^{1}$
\end{abstract}

\section{Keywords: Justification, Rationality, Gradable Adjectives}

\footnotetext{
${ }^{1}$ This paper has benefited from discussions with Robert Audi, Matthew Babb, Selim Berker, Paul Blaschko, Fabrizio Cariani, David Christensen, Jamie Dreier, Andy Egan, Jane Friedman, Anthony Gillies, Robert Henderson, Christopher Kennedy, Justin Khoo, Cameron Domenico Kirk-Giannini, Keith Lehrer, Chad Marxen, Paul Pietroski, Mark Richard, Luís Pinto de Sá, Joshua Schechter, Julia Staffel, and two anonymous reviewers from this journal as well as feedback from sessions at the Central division meeting of the American Philosophical Association and the Congress of the Canadian Philosophical Association. I especially want to thank Stew Cohen, Juan Comesaña, and Jonathan Weinberg for reading early drafts of this paper and serving as members of my qualifying paper committee and Peter van Elswyk for providing extensive comments during the revision process.
} 


\section{INTRODUCTION}

How does the rationality of a belief relate to its justification? Do rational belief and justified belief come to the same thing, or are they distinct properties that a belief might possess? On one side of the debate, we have those who take rationality and justification to be identical:

\section{Identity}

Identity theorists take it that, while there are two separate terms for the rationality and justification of belief, these terms pick out the same property. This view is captured by epistemologists like Stewart Cohen, who when discussing rationality and justification simply says, "distinguishing between rational beliefs and justified beliefs does not make any sense." 2 On the Identity view, it is a mistake to attempt to offer distinct theories of rationality and justification. Because they come to the same thing, any account that distinguishes between the two necessarily goes astray.

On the other side of the dispute, we have those that hold that the rationality and justification of belief come apart:

\section{Independence}

According to Independence thinkers, the justification of a belief is distinct from its rationality. 'Rational' picks out a different quality of a belief than does 'justified.' As Alvin Goldman says, "since 'rational' and 'justified' are different terms of appraisal, rules of rationality might well be distinct from rules of justification." ${ }^{3}$ Independence accounts of rationality and justification attempt to show how the two are distinct, demonstrating that there is more to whether a belief is rational than whether it is justified.

These views are not without consequence. By prying apart justification and rationality, externalists about epistemic justification can respond to Cohen's New Evil Demon problem, suggesting that the counterpart in the demon world is rational even though they fail to be justified. In fact, Cohen's adoption of Identity is an anticipation of just this type of response by externalists. ${ }^{4}$

One argument that is offered in favor of Identity is that, when used to describe belief, 'rational' and 'justified' are synonyms. Critiquing Independence, Cohen explicitly offers this rationale, arguing that "'[R] easonable' and 'rational'

\footnotetext{
${ }^{2}$ See Cohen (2016), p. 846. Others who equate justification and rationality include Cohen (1984), p. 283, Dogramaci (2015), p. 777, Fumerton (1995), p. 19, Huemer (2001), p. 22, and Smithies (2012), p. 777. Though Bach (1985) does take rationality to be closely related to an internalist conception of justification, which may put him in this camp, he also takes there to be two divergent understandings of justification.

${ }^{3}$ See Goldman (1986), p. 60.

${ }^{4}$ See Cohen (1984), p. 283 and (2016), pp. 845-846. Other, more recent authors who hold that there is a divergence between justification and rationality include Jackson (2011), who puts the distinction to use in criticizing phenomenal conservatism, and Sylvan (ms.), who hopes to illustrate how rationality corresponds to subjective reasons while justification aligns with objective reasons. Littlejohn (2012) and Lyons (2013) both draw on the distinction in arguing for externalism.
} 
are virtual synonyms for 'justified'." If 'rational' and 'justified' are synonyms, then they can be employed interchangeably with no change in meaning. Michael Huemer takes a use of 'rational' to be equivalent to a use of 'justified' saying, "Another word for what is justified, or should be done or believed, from the firstperson perspective, is "rational." 6 Sinan Dogramaci says as an aside that the terms can be used interchangeably - "Rationality, justification, reasonableness: same thing. Use whichever word you like." 7 - and Declan Smithies contends that it is no different to say that one is justified or rational remarking, "To say that one has justification to believe a proposition is to say that it is rational or reasonable for one to believe it." ${ }^{8}$ A number of epistemologists also take such a view for granted, using 'rational' and 'justified' interchangeably. ${ }^{9}$ If Cohen is correct that 'rational' and 'justified' are synonymous, then the defender of Independence will be unable to claim that the rationality and justification of belief are distinct properties.

In this paper, I will shift the burden of proof back to the defenders of Identity. I will do this by making the case that 'rational belief' is not synonymous with 'justified belief' and that 'rational' and 'justified' occupy distinct semantic categories. There are cases, for example, in which 'justified' and 'rational' behave quite differently when used to modify belief: ${ }^{10}$

\section{Shooters Game}

Frank and Joe are both fans of the South City Shooters basketball team. Last night, Frank went to the game and saw the Shooters victory. He took a look at the final scoreboard and saw that the Shooters won 88-70. Joe, on the other hand, did not attend the game but nevertheless heard the next day from a co-worker that the Shooters had won.

Both Frank and Joe are justified in believing the Shooters won the game. If Cohen is correct that 'justified' and 'rational' are synonymous regarding belief, then the truth values of the following should march in lockstep:

(1) Frank and Joe are both justified in believing that the Shooters won.

(2) Frank and Joe are both rational in believing that the Shooters won.

(3) Frank is more justified than Joe in believing that the Shooters won.

(4) Frank is more rational than Joe in believing that the Shooters won.

${ }^{5}$ See Cohen (1984), p. 283.

${ }^{6}$ See Huemer (2001), p. 22.

${ }^{7}$ See Dogramaci (2015), p. 277.

${ }^{8}$ See Smithies (2012), p. 274.

${ }^{9}$ See Fumerton's (1995) introduction and Wedgwood (2012), p. 280, amongst others.

${ }^{10}$ Cohen (2016) proposes the synonymy of 'rational' and 'justified' as a solution to clear up worries about the use of the technical term 'epistemic justification' within epistemology. My observations concerning justification and rationality will not undermine Cohen's thought that 'epistemic' is not a useful way to begin theorizing about normative requirements on belief, but they will put pressure on the thought that justified belief can simply be thought of as rational belief. 
This prediction obtains for (1) and (2) - It is true to say that Frank and Joe are both justified and rational in believing that the Shooters won. The truth values of (3) and (4), however, come apart. While it is true to say that Frank is more justified than Joe in believing that the Shooters won, it is not true to say that Frank is more rational than Joe in believing that the Shooters won. This demonstrates that 'justified belief' and 'rational belief' behave in distinct ways at the tops of their scales, a first clue that they are not synonymous. In what follows, I will make good on the thought that they are not synonymous, showing that 'rational' and 'justified' are distinct types of gradable adjective. I will begin by motivating the distinction between relative and absolute gradable adjectives in Section 1, arguing in Section 2 that 'rational' is an absolute gradable adjective and then in Section 3 that 'justified' is a relative gradable adjective. I will then draw out the philosophical implications of these results in Section 4, concluding that, because 'rational belief' and 'justified belief' are not synonymous, the burden of proof in the debate is on those who would argue that the rationality and justification of belief are identical properties.

\section{Gradable Adjectives, Relative and Absolute}

\subsection{Relative Gradable Adjectives}

The orthodox view of gradable adjectives is that they come in two varieties, relative gradable adjectives and absolute gradable adjectives, henceforth RAs and AAs. ${ }^{11}$ Relative gradable adjectives, adjectives like 'tall,' 'large,' 'long,' and 'expensive,' are characterized by an underlying degree scale on which objects in the domain fall. ${ }^{12}$ Because this scale imposes an ordering, the truth or falsity of uses of comparative constructions depends on this underlying structure. For example, (5) is true just in case John has a greater degree of height than Harry:

(5) John is taller than Harry.

This ordering, however, is not all that goes into determining whether (6) is true:

(6) John is tall.

The truth of (6) also depends on a threshold on the underlying scale. If the degree of John's height is clearly greater than the threshold, then (6) is true, and if the degree of his height is clearly lower, then (6) is false. ${ }^{13}$ The threshold

\footnotetext{
${ }^{11}$ For those who distinguish between absolute and relative gradable adjectives, see Kennedy (2007), Kennedy and McNally (2005), Rusiecki (1985), and Unger (1975). Rotstein and Winter (2004) also catalog various features of gradable adjectives with an emphasis on the distinction between total and partial absolute gradable adjectives.

${ }^{12}$ Though there is an account running through Fine (1975), Kamp (1975), Klein (1980), Larson (1988), and Pinkal (1995) that emphasizes quantifications over possible precisifications of the adjective's extension, the scale view adopted by Cresswell (1977), Heim (2000), and von Stechow (1984) is used here due to its advantages in characterizing the distinction between absolute and relative gradable adjectives Kennedy (2007).

${ }^{13}$ Even tough relative gradable adjectives have long been thought to have a contextual threshold as part of their semantics - see Barker (2002), Bartsch and Vennemann (1972),
} 
in question is contextually determined - the degree of height which a primary school child must possess to be considered tall is much lower than the degree that a basketball player must possess.

The contextual thresholds of RAs can be adjusted to differentiate between individuals that differ in the middle of the underlying scale. ${ }^{14}$ In a selection task with two heaps of sand, (7) is felicitous even if the piles of sand are not particularly tall, so long as one is taller than the other:

(7) Point to the tall one.

RAs thus have an accommodating contextual threshold in that it can be adjusted to differentiate between many points on the underlying degree scale. Relative gradable adjectives lose this feature, however, at the extreme ends of their scales. If I am at a professional basketball game looking at two players well above seven feet, or at a national park admiring two very tall redwoods, (7) is infelicitous. This infelicity demonstrates that, though RAs can be used to distinguish between objects that fall in the middle of their degree scales, their contextual thresholds cannot always be adjusted to differentiate between objects that fall on the extreme ends of the degree scale.

Another feature of relative gradable adjectives is that they always give rise to Sorites paradoxes. With 'tall,' the paradox gets going with (8):

(8) For whatever height you are, one inch of height does not change whether you are tall or not.

The trouble of course is created by the fact that (8) seems true. This can be explained by the fact that RAs cannot be used to pick out a maximally specific degree on the underlying scale. As previously noted, an object falls within the extension of an RA like 'tall' if it possesses a degree of height that is clearly greater than the relevant threshold, a description meant to accommodate for borderline cases. Even though there are basketball players who are obviously tall and others who are not, there are others that it is unclear whether they should be classified as tall or short, and may even seem right to say that they are neither. This vagueness makes it such that (8) is intuitively correct, leading to the Sorites.

\subsection{Absolute Gradable Adjectives, Total and Partial}

Like relative gradable adjectives, absolute gradable adjectives like 'dry,' 'straight,' 'pure,' and 'empty' can be used in comparatives. Every eligible object in the

Bierwisch (1989), Cresswell (1977), Fine (1975), Kamp (1975), Klein (1980), Lewis (1970), Pinkal (1995), Sapir (1944), von Stechow (1984), and Wheeler (1972) - the emphasis on objects that "stand out" relative to the threshold against which they are being measured can be found in Rotstein and Winter (2004), Kennedy (2007), and Kennedy and McNally (2005).

${ }^{14}$ See Kennedy (2007), Kyburg and Morreau (2000), Sedivy et al. (1999), and Syrett et al. (2006 and 2010). 
domain is assigned a certain degree on the underlying scale, making (9) true so long as the mug is filled to a greater degree than the cup:

(9) The cup is emptier than the mug.

Furthermore, just as with RAs, this degree scale is not all that goes into determining whether (10) is true:

(10) The cup is empty.

The accuracy of (10) depends on whether the fullness of the cup falls within a certain range. Unlike with RAs, however, this range cannot be characterized as a contextual threshold that can be adjusted simply by distinguishing between two points in the degree scale. Supposing that the mug is three quarters full and the cup only halfway, (9) is still true, but the following command is infelicitious:

(11) \#Point to the empty one.

AAs thus do not have thresholds that are contextually accommodating in the middle of their scales as do RAs.

The infelicity of (11) in the above case may seem analogous to the case of the tall basketball players or the tall redwoods. Why not say that, just like with RAs, there are parts of the scale that a contextual threshold cannot distinguish between? What separates the infelicity of (7) from the infelicity of (11) is that, in the former case, the infelicity occurs with two objects that are at the scale's extreme, while in the latter case, the infelicity occurs with objects in the middle of the scale. The cups are three quarters and half full, whereas both basketball players, and both trees, are very tall. This asymmetry is reinforced by the fact that, while RAs cannot be used to differentiate between objects on the extreme end of a scale, AAs can. Consider, for instance, a cup that is completely empty and a mug that has a swallow of liquid left. In such a case, both (9) and (11) are felicitous. RAs and AAs thus differ in the following way - RAs can be used to distinguish between objects in the middle of a scale but not at the scale's extreme, while uses of AAs cannot distinguish between objects in the middle of the scale, but can at the end of the scale.

Because absolute gradable adjectives do not possess a threshold that is contextually flexible in the same way as relative gradable adjectives, there are cases in which they do not give rise to Sorites paradoxes. If the cup has exactly one ounce of liquid in it and is for that reason not empty, there is no temptation to accept a sentence like (12), which is essential for the paradox to get started:

(12) For however full a container is, one ounce of liquid does not change whether it is empty or not.

If the cup has exactly one ounce of liquid in it, taking away that ounce of water makes it true that the cup is empty, making (12), the first step along the route to the paradoxical result, clearly false. This is because there is a clear cutoff 
point for the distinction between empty and not empty. With 'tall,' it is not clear at what point adding one inch of height will take someone from not being tall to being tall, but in the case of the empty glass, it is clear when taking away another ounce of liquid will make it empty. ${ }^{15}$

Absolute gradable adjectives come in two forms - total and partial. Total AAs require the absence of a particular property. A dry table is not wet to any degree, a straight line is not at all bent, and pure gold does not contain any impurities. Partial AAs, on the other hand, require only that objects possess a minimal degree of the property described. A table is wet if it has even a small degree of wetness, a line is crooked if it forms an angle of just under one hundred and eighty degrees, and gold is impure if it contains some amount of impurity. ${ }^{16}$ AAs often come in pairs - wet and dry, bent and straight, impure and pure, open and closed - with one of the pairs behaving as a total AA and the other a partial AA. This is the case so long as the AAs in question are contradictories. 'Wet,' for instance, is synonymous with 'not dry,' and 'dry' with 'not wet,' yielding the result that 'wet' and 'dry' are a total/partial pair. 'Empty' and 'full,' on the other hand, are not contradictories in that 'empty' does not simply mean 'not full,' so 'empty' and 'full' do not form a total/partial pair. 'Empty' and 'full' are, in fact, both total AAs, as both can create failures in the "point to" selection test.

Even though many uses of total AAs require the absence of a particular property, it is possible to create a context in which approximations are also considered to satisfy sentences attributing total AAs. It can be acceptable to say that a table is dry even if is slightly damp when the purpose is to cover the table with a tablecloth that you do not want to get soaking wet. Similarly, it can be acceptable to say that a glass is full even if it could be slightly more full than it is. Total AAs can thus give rise to Sorites paradoxes in such contexts. Does adding one more drop of water change whether the table is dry or not? Does taking away a drop of water prevent the cup from being full? Negations of partial AAs exhibit the same characteristic, as 'not bent,' 'not wet,' and 'not impure' behave like total AAs. Absolute gradable adjectives that do not give rise to the Sorites in any context are partial AAs and the negations of total AAs. Because partial AAs require that an object possess a minimal degree of the property in question, objects that possess none of the property will then falsify the crucial premise of the Sorites:

(13) For however wet a table is, taking away one drop of water will not make it dry.

\footnotetext{
${ }^{15}$ Burnett (2014), Kennedy (2007), and Pinkal (1995) all note cases in which sentences containing AAs fail to give rise to the Sorites paradox.

${ }^{16}$ Resources on the distinction between absolute and relative gradable adjectives include Burnett (2014), Cruse (1986), Kennedy (2007), Rotstein and Winter (2004), and Yoon (1996). For a similar distinction, see Kamp and Rossdeutscher (1994) on universal and existential adjectives.
} 
If there is only a single drop of water on the table, then (13) will be false of that table. Likewise, since negations of total AAs are synonymous with partial AAs, negations of total AAs also do not give rise to Sorites paradoxes. ${ }^{17}$

The lack of Sorites-paradoxical results for partial AAs and negations of total AAs is associated with the presence of a top-closed or bottom-closed scale. A table can be maximally dry, and thus 'wet' does not give rise to a Sorites march, whereas, for the RA 'tall,' it is not possible to be maximally tall. For however tall you are, it is always possible to possess a degree more height. This makes it such that there is no clear cutoff, no point where there is an obvious transition from not being tall to being tall, and thus paradoxical marches become a possibility. With 'wet,' on the other hand, because there is a distinctive cutoff between maximal dryness and partial dryness, there are points in the scale that do not give rise to the Sorites, as there is a clear transition from not being wet to being wet to a small degree. ${ }^{18}$

Because AAs have a top-closed scale, another test that can help distinguish between RAs and AAs is whether modifiers like 'completely,' 'totally,' and 'perfectly' can be used to pick out a maximal element. ${ }^{19}$ Maximal degree constructions are thus felicitous for total AAs:

(14) The cup is completely empty

(15) The table is completely dry

RAs, however, do not accept similar attempts at modification:

(16) \#The basketball player is completely tall

This test, unfortunately, is not infallible, as there are uses of maximality modifiers that are synonymous with 'very.' ${ }^{20}$ Consider, for example, the use of 'completely' in (17):

(17) I am completely jealous that you are vacationing in the Bahamas

Even though 'jealous' is a gradable adjective, the use of 'completely jealous' in (17) hardly means that there is no greater degree of jealousy. This can be seen via an entailment test. When 'completely' is synonymous with 'very,' it is possible that something can possess the property in question to an even greater degree, while when completely is used to pick out the maximum point on a scale, this is not possible:

\footnotetext{
${ }^{17}$ For more on the Sorites and absolute gradable adjectives, see Burnett (2014) and Kennedy (2007).

${ }^{18}$ For more on how the presence of maximal elements in the scale are distinctive of AAs, see Kennedy (2007), pp. 32-40.

${ }^{19}$ See Burnett (2014), Cruse (1986), Kennedy (2007), Kennedy and McNally (2005), and Rotstein and Winter (2004).

${ }^{20}$ Both Kennedy (2007), pp. 34-35, and Kennedy and McNally (2005), p. 354, note this possibility.
} 
(18) I am completely jealous that you are vacationing in the Bahamas, but my wife is even more jealous

(19) \#The cup is completely full, but you could still fill it up a bit more

Maximality modifiers, then, must be used with caution when testing for the presence of a closed scale, an issue to which we will return in our discussion of 'rational' and 'justified.'

\subsection{VAGUeness AND ImPRECISION}

How should we characterize the contextual variation allowed by AAs? Why under some circumstances can the use of an AA still lead to a Sorites paradox? The difference between the contextual variation in RAs and AAs is best understood as the distinction between vagueness and imprecision. ${ }^{21}$ The guiding thought with imprecision is that a particular point plays a central role in the meaning of the term used. For instance, if it is said that Mary arrived at three o'clock, the precise time three o'clock plays a crucial role in the meaning of the sentence. Such a statement could be made imprecisely, if Mary arrived at 2:58 or 3:02, for instance, but this does not undermine the thought that precisely 3:00 constrains the meaning of the assertion. With gradable adjectives, the maximal or minimal points on the scale play a central role in the meaning of AAs. A glass that is completely full counts as full in any context, but when the standards of 'full' are relaxed, this is not due to a contextually determined threshold, as with RAs, but merely imprecise uses of 'full,' a term which depends for its meaning on maximal fullness. When the standards are thus relaxed and we begin speaking imprecisely, a degree or so below complete fullness counts as full and it becomes unclear at what lesser degree of fullness a glass stops counting as full. ${ }^{22}$

A test to distinguish between vague and imprecise predicates is whether the gradable adjective in question allows for natural precisification. ${ }^{23}$ The mean-

\footnotetext{
${ }^{21}$ Pinkal (1995) and Kennedy (2007) address the difference as it applies to gradable adjectives while Krifka (2002 and 2007), Lakoff (1973), Sadock (1977), and Sauerland and Stateva (2007) survey the difference between vagueness and imprecision more generally.

${ }^{22}$ It is worth noting that there is disagreement about whether imprecision is truthconditional. Those who take all loose talk to be strictly speaking false include Kennedy and McNally (2005), Lasersohn (1999), Sperber and Wilson (1985), and Unger (1975), while those who have offered accounts on which imprecise uses can be true include Krifka (2002 and 2007), Lewis (1979), Sauerland and Stateva (2011), and Solt (2014). For my thesis that 'rational' and 'justified' occupy different semantic categories, however, it will not be necessary to come down on the issue of whether imprecise use effects the truth conditions of the relevant terms.

${ }^{23}$ Technically speaking, vagueness and imprecision are properties, not of particular gradable adjectives, but of particular uses of gradable adjectives. As shorthand, I will speak of vague and imprecise terms for terms that can give rise to vagueness and imprecision in particular contexts, but vagueness and imprecision should always be thought of as a property of specific uses of gradable adjectives. Thank you to an editor of this journal for helping me to clarify the relationship between instances of vagueness and imprecision and the terms that give rise to these phenomena.
} 
ings of vague terms can only be precisified by introducing stipulative definitions, whereas with imprecise terms, natural language contexts can independently precisify the term. With imprecise AAs, contexts can be established in which only the maximal degree satisfies the standards. Even though a sports stadium can be described as empty on a day of low attendance, nothing but complete emptiness will be under consideration when a construction boss overseeing the demolition of the stadium inquires whether it is empty. It is thus possible to eliminate borderline cases from consideration. Twenty-two karat gold only permits impurities up to eight percent, but a jeweler may establish a higher standard for 'pure' with a use of (20):

(20) The gold for the ring needs to be pure, but this gold is twenty-two karat, so it will not do.

Similarly, if a surface is being used for an experiment and needs to be so dry that it has no water molecules on it at all, a scientist can use 'dry' to pick out this property:

(21) The table needs to be dry, but the surface still has a few stray water molecules, so it will not do.

Vague RAs, however, allow no such precifications. Not only do RAs not have closed scales, thus not allowing for precisification to a maximal or minimal degree, but strict cutoffs cannot be created either. The world record height for a redwood tree is 380 feet, but a forester that is looking for tall trees cannot create a cutoff for 'tall' by a use of (22):

(22) \#I'm looking for tall redwoods, but this one is 375 feet tall so it will not do.

Thus, RAs cannot be naturally precisified while AAs can, securing that uses of RAs are vague while uses of AAs are imprecise.

The fact that AAs accept natural precisification and RAs do not can also be demonstrated by answers to queries. If before the demolition of the stadium, the construction foreman asks the owner of the stadium whether it is empty, the owner speaks inappropriately if they say (23) when there is one person left in the stadium:

(23) The stadium is empty

For the purposes of demolition, only a completely empty stadium will do, and therefore 'empty' is precisified to mean no people whatsoever. The same cannot occur, however, with an RA like 'tall'. Suppose that a record-hunter heads to the national park looking for a record-setting redwood. Even though the park does not have any trees over 380 feet, the park ranger cannot for this reason say (24):

(24) The park does not have any tall redwoods 
Even though the purpose of the conversation is finding a record-setting redwood, this does not precisify the meaning of 'tall' up to any redwoods that are record-setting. The key difference between vague and imprecise adjectives then is that imprecise adjectives can be made more precise, possibly even establishing strict cutoffs, while vague adjectives cannot.

Assaf Toledo and Galit Sassoon argue that the orthodox view is wrong to think that absolute gradable adjectives are used imprecisely. They present contrasts of total AAs that they claim tell against the standard account:

(25) This kitchen knife is clean.

(26) This surgical instrument is clean.

(27) This child's shirt is dirty.

(28) This tuxedo is dirty.

If total AAs are used to pick out the maximal element on the underlying scale, then why are the standards for uses of (26) and (28) more demanding than the standards for uses of (25) and (27)? This extends to other examples as well why do we not hesitate, for instance, to say wine glasses are full when they are only filled halfway? ${ }^{24}$ According to Toledo and Sassoon, such cases show that the interpretation of AAs cannot just depend on the maximal element in the scale. Rather, other factors must be considered as well, like the type of object of which they are being ascribed, generating shifting standards when applied to kitchen knives and surgical instruments.

Despite the contentions of Toledo and Sassoon, these examples do not show that the standard view is inadequate. All of their examples can be predicted by the orthodox account as permissible imprecise uses. Imprecise uses are acceptable whenever the property they pick out is good enough for the practical purposes at hand. In the case of kitchen knives and surgical instruments, the characteristic use of the latter requires much more so far as cleanliness is concerned, so the standards for uses of (26) are more demanding than uses of (25). Likewise, tuxedo's are worn in circumstances where being spotlessly clean is the norm, so acceptable uses of (28) require less dirt than those of (27). What about wine glasses? The standard view predicts that if it is permissible to ascribe fullness to a wine glass when it is not maximally full, this is because there is some practical goal that can be satisfied by wine glasses that are less than completely full. This prediction is confirmed - amongst wine connoiseurs it is common knowledge that a wine glass is only filled halfway in order to allow the wine to be properly aerated, the same purpose for which wine decanters are used. Having room to swirl the glass allows the aroma of the wine to be released. ${ }^{25}$ Thus, there is a practical purpose at play when half full wine glasses are described as full, allowing such data to be captured by the orthodox account.

\footnotetext{
${ }^{24}$ See Toledo and Sassoon (2011) with the wine glass example originating in McNally (2011).
}

${ }^{25}$ See Fox (2011) and McCarthy and Mulligan (2015). 


\section{2 'Rational' as an Absolute Gradable Adjective}

My contention is that 'rational' and 'justified' behave differently at the tops of their scales in Shooters Game because they are different classes of gradable adjective. In what follows, I will argue that 'rational' is an AA while 'justified' is an RA, predicting that the meaning of 'rational' is tied to the uppermost element in its scale while 'justified' is not. To begin with, 'rational' is clearly gradable. It functions felicitously both in comparatives and with degree modifiers:

(29) Mary's beliefs are more rational than John's.

(30) Mary's belief that it is raining outside is not very rational. ${ }^{26}$

'Rational' is obviously a gradable adjective, but a gradable adjective of what stripe? Absolute or relative? Total or partial? To begin with, it has already been argued that rationality is an absence of any element of irrationality. Roy Sorensen claims that being rational has in common with other total AAs that it is the absence of certain properties, instead of the presence of some property, that makes one rational:

"My thesis is that 'rational' is an absolute concept like 'flat' and 'clean.' Absolute concepts are best defined as absences. In the case of flatness, the absence of bumps, curves, and irregularities. In the case of cleanliness, the absence of dirt. Rationality, then, is the absence of irrationalities such as bias, circularity, dogmatism, and inconsistency."27

Total AAs can be identified because their uses require the absence of a particular property, and if Sorensen is correct, rationality is the absence of the features that contribute to irrationality, making 'rational' a total AA.

Another reason to think that 'rational' is a total AA is because it cannot be used with a contextually accommodating threshold in the middle of its scale. Suppose that, upon looking out the window and seeing no rain outside, Mary forms the belief that it is raining. John, on the other hand, forms the belief that it is not only cloudy and raining, but also hailing. In such a case, (31) is an infelicitous request even though the comparative claim (29) is true:

(31) \#Point to the one who believed rationally

Therefore, even though 'rational' is gradable, its unmarked form cannot be used to distinguish between beliefs in the middle of the underlying scale.

'Rational' can, however, be used to distinguish two individuals that are at the extreme ends of the scale. If Mary sees that it's raining heavily outside and

\footnotetext{
26 'Rational' can modify a number of different objects beyond just beliefs - we also often speak of rational persons and rational actions, for instance. Though I think that the points made here can be extended to the other uses of 'rational' as well, I will confine my attention in this paper to the rationality of belief.

${ }^{27}$ See Sorensen (1991), p. 473.
} 
believes as much while John, seeing the heavy rain, believes it is only lightly raining, then (31) is felicitous. Furthermore, 'rational' does not always give rise to Sorites paradoxes. When Mary's beliefs are irrational due only to one belief formed on the basis of wishful thinking, then (32) is clearly false:

(32) Wherever a set of beliefs falls on the rationality scale, eliminating one irrational belief does not change whether the set is rational or irrational

Subtracting a belief that is based on wishful thinking from Mary's set of beliefs does make that set rational. This is due to the concept of rationality possessing a top-closed scale, making borderline cases at the top of the scale impossible. The modifier 'completely' also speaks to the presence of a closed scale of rationality. When Mary correctly believes that it is raining heavily, then (33) is felicitous:

(33) Mary is completely rational in her belief

As mentioned in Section 1.2, tests utilizing maximality modifiers must be used with caution. In order to make sure that 'completely' in (33) is not synonymous with 'very,' we also need to use an accompanying entailment test like the one in (34):

(34) \#Mary is completely rational in her belief, but she could have formed an even more rational belief

Because (34) is a contradiction, we can see that, in the case of rationality, the maximality test does indicate a top-closed scale.

Because 'rational' neither is always contextually variable nor always gives rise to Sorites paradoxes, it is clear that it is an absolute gradable adjective. This is not to deny that it is possible to create a Sorites context with 'rational.' 'Rational' and 'irrational' are contradictories, and thus the total AA should be capable of generating the Sorites when used imprecisely. 'Irrational' is a partial AA as a set of beliefs that is irrational even to a small degree is irrational, and 'rational' is total for it is true of sets of beliefs that possess rationality to a maximal degree. Sure enough, 'rational' does give rise to Sorites-paradoxical results. Consider a case where a brilliant scientist is described as having rational beliefs even though he has one belief based on wishful thinking. Will adding one more belief that is not supported by his evidence make his beliefs irrational? Because it is not clear that one more irrational belief would make his beliefs irrational, the crucial premise of the Sorites takes hold. The partial AA, on the other hand, does not yield this result because it is associated with a strict cutoff. This is true of 'irrational,' as a believer who does not possess any degree of irrationality cannot be described as irrational in any context.

Because 'rational' is an absolute gradable adjective, many of its ordinary uses are imprecise. Consider a case in which a reporter is collecting comments from passers-by about whether or not they think there is a wage gap between men and women. As soon as the reporter starts interviewing a particular subject, it 
is clear that they are afflicted with some kind of psychosis. After the interview, the reporter indicates to the camera crew that the footage will not be helpful saying, (35):

(35) We need someone that has rational beliefs about whether there is a wage gap.

In this particular context, the reporter rules out interviewees who have irrational beliefs due to psychosis. It is possible though through natural precisification to require even more of interviewees. Suppose that a researcher is attempting to measure the degree to which implicit bias effects beliefs about the wage gap. After a potential participant tests positively for a small level of implicit bias, the researcher utters (35). In this case, the use of (35) rules out even those subjects with a small degree of implicit bias, ruling out a far larger swath of candidates than merely those that are psychotic. Natural precisification is thus possible for 'rational' when discussing the rationality of belief.

\section{3 'Justified' as a Relative Gradable Adjective}

Like 'rational,' 'justified' is a gradable adjective, permitting comparatives and accepting degree modifiers:

(36) Frank is more justified than Joe in believing the Shooters won.

(37) Frank is very justified in believing the Shooters won.

The question, then, is whether 'justified' is an AA or RA. A preliminary motivation for taking 'justified' to be a RA is that many have argued that it is a contextual matter whether or not someone is justified in their beliefs. On this picture, whether the evidence a subject has is sufficient to make them justified in believing that $p$ depends on contextual factors. One way of cashing out this idea is by appealing to the practical import of the situation - when more is at stake, the argument goes, the evidential standards for being justified in believing $p$ go up, while when not much hangs on whether $p$, the standards for justification are relatively weak. ${ }^{28}$ Thus, the fact that justification is already taken by many to be a contextual matter lends plausibility to the thought that 'justified' might function with a contextual threshold.

\footnotetext{
${ }^{28}$ Cohen's (1998) view is that to have a justified belief is to be able to rule out all salient error possibilities, with contextual effects altering what is salient (p. 292, fn. 11). Wedgwood (2008) follows Cohen in taking standards of justification to vary with context, though his framework differs from Cohen's in that he does not take justification to require ruling out all live possibilities. Fantl and McGrath (2002) take which beliefs are justified to be effected by more than just evidential considerations, including whether one can act as if $p$ given the stakes of one's practical situation, while Foley (2000) puts a similar requirement on the standards for responsible belief. Even though these latter accounts are not explicitly posed as such, each could receive a contextualist regimentation. These views are all distinct from the pragmatic encroachment about knowledge of Fantl and McGrath (2010), Stanley (2005), and Weatherson (2012), though Cohen (1998) is motivated to adopt his view by his knowledge contextualism, claiming that knowledge gets its contextual nature from that of justification (p. 97).
} 
'Justified' also functions like a RA in selection tasks. The following study was conducted with twenty-one native English speakers via Amazon Mechanical Turk. The subjects responded to the first two items as control cases. Participants were shown Figure 1 and were given the following prompt: "If I asked you to point at the straight one, which would you point to?" Participants were then shown Figure 2 accompanied by the following prompt: "If I asked you to point at the tall one, which would you point to?" The images for the questions were chosen because there was a small but noticeable difference between the two objects pictured, one line is noticeably straighter than the other, and one person is noticeably taller than the other. This distinction between the two then makes the selection task possible, as one possesses more of the target property than the other. As expected, because 'straight' is an AA, the majority of participants answered that neither line was straight, whereas because 'tall' is a RA, the majority of participants said that person 1 was tall.

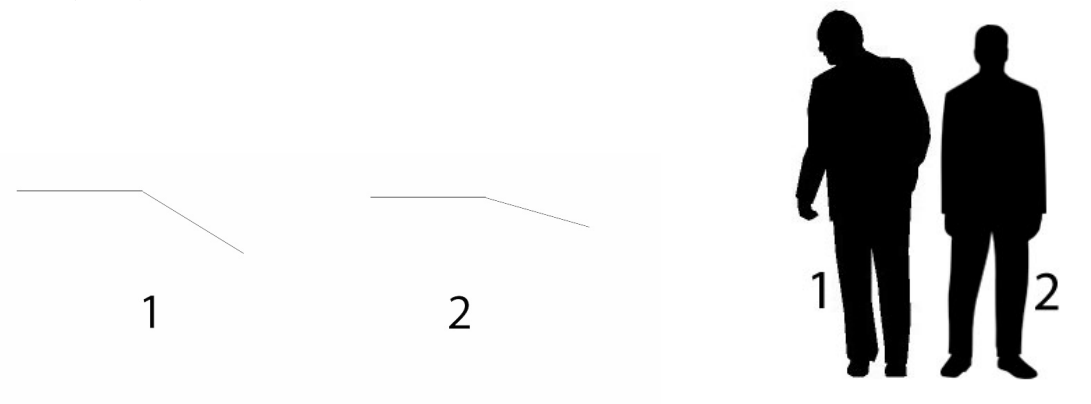

Figure 1: Which is Straight?

Figure 2: Which is Tall?

Participants were then presented with two vignettes. The first was designed to see to what extent the behavior of 'rational' mirrors that of other AAs:

\section{Sunny Day}

It is a bright and sunny day, and there is not a cloud in the sky. Mary looks out the window and forms the belief that it is cloudy and raining outside. John looks out the window and forms the belief that it is not only cloudy and raining, but also hailing. If I asked you to point at the one with rational beliefs, who would you point to?

The second scenario was intended to ascertain to what extent 'justified' behaves like other RAs:

\section{Tree Planting}

Bill and Jay both want to grow 100 foot tall trees in their backyards. From information they got when they bought their saplings, Bill knows there is a $40 \%$ chance that his tree will reach 100 feet, and Jay knows that there is a $20 \%$ chance that his tree will reach 100 feet. If I asked you 
to point at the one who is justified in believing that his tree will reach

100 feet, who would you point to?

As with Figures 1 and 2, the intention with these cases was to discern if it is possible to differentiate between the two subjects using the unmarked forms of gradable adjectives. The aim was also to keep the cases described in the relative middle of the scales. Neither Mary nor John are at the top of the scale of rationality, and the justification Bill and Jay have for the growth of their respective trees does not even make it more likely than not that their trees will reach 100 feet. The results then confirmed that the behavior of 'justified' more closely resembles RAs while 'rational' resembles AAs. The majority of participants selected Bill as justified, while with 'rational,' the majority of respondents chose that neither Mary nor John was rational.

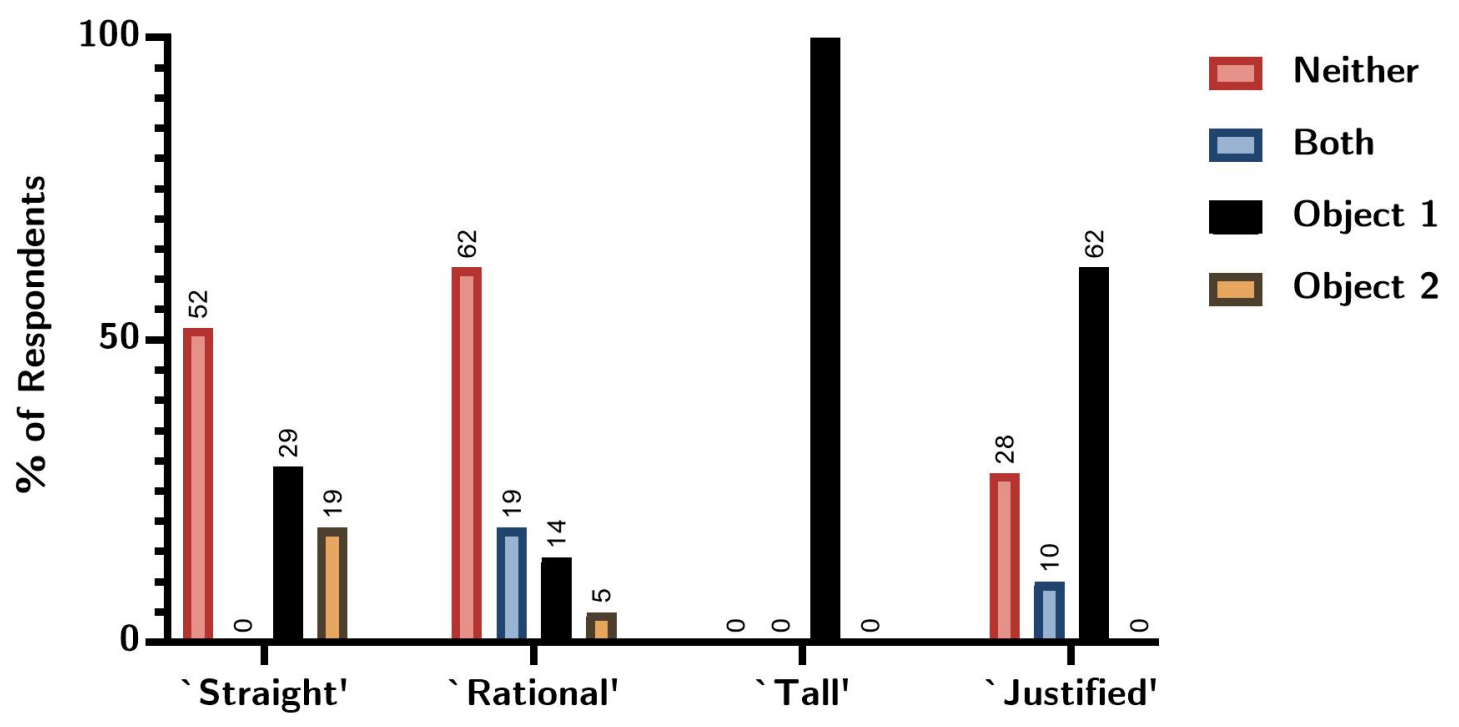

Figure 3: Survey Results

The studied selection tasks permit unmarked RAs to differentiate between objects that fall in the middle of their degree scales. At the extremes of the degree scales, however, such differentiation is not possible for unmarked RAs. Because Joe and Frank both have strong evidence that the Shooters won, even though Frank is more justified than Joe, we cannot differentiate between them with a use of (38):

(38) \#Point to the one who is justified in believing that the Shooters won

What goes wrong with (38) is that 'justified' is an RA. Both Joe and Frank are very justified in believing that the Shooters won, and even though Frank is more justified than Joe, this does not permit distinguishing between them using 
the unmarked form of 'justified.'

'Justified' also gives rise to Sorites-paradoxical results. Suppose that a scientist has set out to discover if all ravens are black. They have not yet observed enough black ravens to be justified in believing the universal generalization. At some point, they will have observed enough ravens to be justified in believing that they are all black, but if we increase their justification degree by degree, asking if they would have been justified if they had observed one more raven, there will be no clear cutoff point. Thus, it seems like (39) is true:

(39) However justified a belief is, adding a degree more of justification will not change whether or not the belief is justified

'Justified' thus behaves like RAs in creating Sorites paradoxes, unlike 'rational.' This is because justification does not have a top-closed scale. Even though 'justified' can be modified by 'completely' in (40),

(40) Joe is completely justified in believing that the Shooters won

this is not because 'justified' has a maximal interpretation, as seen in (41):

(41) Joe is completely justified in believing that that Shooters won, but

Frank is even more justified in believing that they won

Because the entailment in (41) goes through, this indicates that 'completely' in (40) means something close to 'very' instead of picking out a maximal degree of justification. It does not appear, then, that 'justified' corresponds to a topclosed scale.

Furthermore, 'justified' does not accept natural precisification. Suppose that Frank and Joe's boss is looking for someone who saw the result of the Shooters

Game in person. The boss refuses to believe anyone who heard about the game secondhand. Even though Joe did not attend the game in person, it is inappropriate to dismiss Joe with (42):

(42) I'm looking for someone who is justified in believing the Shooters won

It would be even more inappropriate to dismiss Joe's testimony with (42) if Joe had both heard from someone else that the Shooters won AND read it in the local newspaper. Thus, 'justified' cannot be precisified to require a certain level of justification, like seeing the game firsthand.

\section{Rationality, Justification, and Demon Worlds}

According to Identity theorists, offering separate theories for rationality and justification is a conceptual mistake. On their view, rational belief just is justified belief, leaving no leeway for externalists to claim that demon world counterparts are rational but not justified. Independence accounts, on the other 
hand, argue that this distinction is veridical - rational belief is not the same as justified belief - and so it is at least possible for the externalist to claim that a belief can be rational without being justified. ${ }^{29}$ In this paper, I have provided enough evidence to rebut the synonymy argument for Identity. Not only are "rational belief" and "justified belief" not synonymous, as can be seen in Shooters Game, but 'rational' and 'justified' are distinct types of gradable adjectives.

One upshot of this is that advocates of Identity must abandon one of their previous arguments for the equivalence of the rationality and justification of belief. Appealing to synonymy will no longer be of any help in arguing for Identity. There are cases, of course, when terms have the same extension but are not synonymous. One of the most famous examples of this is that 'Hesperus' and 'Phosphorus' both refer to Venus even though they have different Fregean senses. This will not be of much help, however, to the Identity theorist. The primary difficulty with 'Hesperus' and 'Phosphorus' is that their meanings diverge in contexts like belief reports, but the meanings of 'rational' and 'justified' fail to march in lockstep even when not embedded in reports of propositional attitudes. Instead, 'rational' and 'justified' are more like 'drowsy' and 'tired' - two words whose meanings are closely related but nevertheless pick out distinct properties. Being tired may be one component of being drowsy, yet 'tired' does not capture the full meaning of 'drowsy.' If this is right though, then the proponents of Identity will have to explain why 'rational' and 'justified' come apart even though the properties they pick out are identical. Identity theorists thus not only lose an argument in favor of their position, but they also are saddled with explaining why rationality and justification are identical even though 'rational' and 'justified' have distinct meanings. If this case cannot be made, then there might be conceptual room after all for the externalist to claim rationality and justification come apart, particularly in cases of global deception.

\footnotetext{
${ }^{29}$ This is not to say that there is anything peculiar to AAs or RAs that make them particularly well-suited to pick out internalist or externalist epistemic properties but just to point out that maintaining a distinction between rationality and justification gives the externalist one more tool for responding to the New Evil Demon Problem. Thank you to an anonymous reviewer for helping me to further clarify the relationship between the argument from synonymy and the externalist response to the New Evil Demon.
} 


\section{REFERENCES}

[1] Bach, Kent. 1985. "A Rationale for Reliabilism." The Monist 68: pp. 248263.

[2] Barker, Chris. 2002. "The Dynamics of Vagueness." Linguistics and Philosophy, 25, no. 1: pp. 1-36.

[3] Bartsch, Renate and Theo Venneman. 1972.The Grammar of Relative Adjectives and Comparison. Linguistische Berichte 20: pp. 19-32.

[4] Bierwisch, Manfred. 1989. "The Semantics of Gradation." In Dimensional Adjectives, ed. Manfred Bierwisch and Ewald Lang. : pp. 71-261. Berlin: Springer-Verlag.

[5] Burnett, Heather. 2014. "A Delineation Solution to the Puzzles of Absolute Adjectives." Linguistics and Philosophy 37, no.1: pp. 1-39.

[6] Cohen, Stewart. 1984. "Justification and Truth." Philosophical Studies 46: pp. 279-295.

[7] Cohen, Stewart. 1998. "Contextualist Solutions to Epistemological Problems: Skepticism, Gettier, and the Lottery." Australasian Journal of Philosophy 76: pp. 289-306.

[8] Cohen, Stewart. 2016. "Theorizing about the Epistemic." Inquiry 59: pp. 839-857.

[9] Cresswell, Max. 1977. "The Semantics of Degree." In Montague Grammar, ed. Barbara Partee: pp. 261-292. New York: Academic Press.

[10] Cruse, D.A. 1986. Lexical Semantics. Cambridge University Press.

[11] Dogramaci, Sinan. 2015. "Communist Conventions for Deductive Reasoning." Nous 49: pp. 776-799.

[12] Fantl, Jeremy and Matthew McGrath. 2002. "Evidence, Pragmatics, and Justification." Philosophical Review 111: pp. 67-94.

[13] Fantl, Jeremy and Matthew McGrath. 2010. Knowledge in an Uncertain World. Oxford University Press.

[14] Fine, Kit. 1975. "Vagueness, Truth, and Logic." Synthese 30: pp. 265-300.

[15] Foley, Richard. 2000. "Epistemically Rational Belief and Responsible Belief." The Proceedings of the Twentieth World Congress of Philosophy 5: pp. 181-188.

[16] Fox, Sue. 2011. Etiquette for Dummies. John Wiley and Sons.

[17] Fumerton, Richard. 1995. Metaepistemology and Skepticism. Lanham: Rowman and Littlefield. 
[18] Goldman, Alvin. 1986. Epistemology and Cognition. Harvard University Press.

[19] Heim, Irene. 2000. "Degree Operators and Scope." In Proceedings of the Tenth Semantics and Linguistic Theory Conference. Ed. by B. Jackson and T. Matthews: pp. 40-64. Ithaca, New York: CLC Publishing.

[20] Huemer, Michael. 2001. Skepticism and the Veil of Perception. Lanham: Rowman and Littlefield.

[21] Jackson, Alex. 2011. "Appearances, Rationality and Justified Belief." Philosophy and Phenomenological Research 82: pp. 564-593.

[22] Kamp, Hans. 1975. "Two Theories of Adjectives." In Formal Semantics of Natural Language, ed. Edward Keenan: pp. 123-155. Cambridge University Press.

[23] Kamp, Hans and Antje Rossdeutscher. 1994. "DRS-construction and Lexically Driven Inferences." Theoretical Linguistics 20: pp. 165-235.

[24] Kennedy, Christopher. 2007. "Vagueness and Grammar: The Semantics of Relative and Absolute Gradable Adjectives." Linguistics and Philosophy 30, no. 1: pp. 1-45.

[25] Kennedy, Christopher and Louise McNally. 2005. "Scale Structure and the Semantic Typology of Gradable Predicates." Language 81, no. 2: pp. 345381.

[26] Klein, Ewan. 1980. "A Semantics for Positive and Comparative Adjectives." Linguistics and Philosophy 4: pp. 1-45.

[27] Krifka, Manfred. 2002. "Be Brief and Vague! And How Bidirectional Optimality Theory Allows for Verbosity and Precision." In Sounds and Systems, Studies in Structure and Chang: A Festschrift for Theo Vennemann. Edited by D. Restle and D. Zaefferer. Berlin: Mouton de Gruyter.

[28] Krifka, Manfred. 2007. "Approximate Interpretations of Number Words: A Case of Strategic Communication." In Cognitive Foundations of Interpretation. Edited by G. Bouma, I. Kramer, and J. Zwarts. Amsterdam: Koninklijke Nederlandse Akademie van Wetenschapen.

[29] Kyburg, Alice and Michael Morreau. 2000. "Fitting Words: Vague Language in Context." Linguistics and Philosophy 23: pp. 577-597.

[30] Lakoff, George. 1973. "Hedges: A Study in Meaning Criteria and the Logic of Fuzzy Concepts." Journal of Philosophical Logic 2: pp. 458-508.

[31] Larson, Richard. 1988. "Scope and Comparatives." Linguistics and Philosophy 11: pp. 1-26. Lasersohn Lasersohn, Peter. 1999. "Pragmatic Halos." Language 75, no. 3: pp. 522-551. 
[32] Lewis, David. 1970 "General Semantics." Synthese 22: pp. 18-67.

[33] Lewis, David. 1979. "Score-Keeping in a Language Game." Journal of Philosophical Logic 8: pp. 339-359.

[34] Littlejohn, Clayton. 2012. "Justification and the Truth Connection." Cambridge University Press.

[35] Lyons, Jack. 2013. "Should Reliabilists Be Worried About Demon Worlds?" Philosophy and Phenomenological Research 86: pp. 1-40.

[36] McCarthy, Ed, and Mary Ewing-Mulligan. 2015. Wine for Dummies. John Wiley and Sons.

[37] McNally, Louise. 2011. "The Relative Role of Property Type and Scale Structure in Explaining the Behavior of Gradable Adjectives." In $P a$ pers from the ESSLLI 2009 Workshop on Vagueness in Communication. Edited by R. Nouwen, R. van Rooij, U. Sauerland and H. Schmitz. Berlin: Springer.

[38] Pinkal, Manfred. 1995. Logic and Lexicon. Dordrecht: Kluwer.

[39] Recanati, Francois. Literal Meaning. Cambridge University Press.

[40] Rotstein, Carmen and Yoad Winter. 2004. "Total Adjectives vs. Partial Adjectives: Scale structure and higher-order modifiers. Natural Language Semantics 12: pp. 259-288.

[41] Rusiecki, Jan 1985. On Adjectives and Comparisons in English. New York: Longman Linguistics Library.

[42] Sadock, Jerrold. 1977. "Truth and Approximations." In Proceedings of the Third Annual Meeting of the Berkeley Linguistics Society. Edited by K. Whistler Jr., R.D. Van Valin, C. Chiarello, J.J. Jaeger, M. Petruck, et al. Berkeley, CA: Berkeley Linguistics Society.

[43] Sapir, Edward. 1944. "Grading: A Study in Semantics." Philosophy of Science, 11: pp. 93-116.

[44] Sauerland, Uli and Penka Stateva. 2007. "Scalar vs. Epistemic Vagueness: Evidence from Approximators." In Proceedings of the Seventeenth Semantics and Linguistic Theory Conference. Edited by T. Friedman, and M. Gibson. Ithaca, NY: CLC Publishing.

[45] Sauerland, Uli and Penka Stateva. 2011. "Two types of vagueness." In Vagueness and Language Use. Edited by Paul Egre and Nathan Klinedinst. Houndmills, Basingstoke: Palgrave Macmillan.

[46] Sedivy, J., Tanenhaus, M., Chambers, C. and Carlson, G. 1999. "Achieving Incremental Semantic Interpretation through Contextual Representations." Cognition 71: pp. 109-147. 
[47] Smithies, Declan. 2012. "Moore's Paradox and the Accessibility of Justification." Philosophy and Phenomenological Research 85: 273-300.

[48] Solt, Stephanie. 2014. "An Alternative Theory of Imprecision." Semantics and Linguistic Theory 24: pp. 514-533.

[49] Sorensen, Roy. 1991. "Rationality as an Absolute Concept." Philosophy 66: pp. $473-486$.

[50] Sperber, Dan and Deirdre Wilson. 1985. "Loose Talk." Proceedings of the Aristotelian Society 86: pp. 153-171.

[51] Stanley, Jason. 2005. Knowledge and Practical Interests. Oxford University Press.

[52] Stechow, Arnim von. 1984. "Comparing Semantic Theories of Comparison." Journal of Semantics 3: pp. 1-77.

[53] Sylvan, Kurt. Manuscript. "On Divorcing the Rational and the Justified in Epistemology."

[54] Syrett, K., Bradley, E., Kennedy, C. and Lidz, J. 2006. "Shifting Standards: Children's Understanding of Gradable Adjectives." In Proceedings of the Inaugural Conference on Generative Approaches to Language Acquisition: pp. 353-364.

[55] Syrett, K., Kennedy C. and Lidz, J. 2010. "Meaning and Context in Children's Understanding of Gradable Adjectives." Journal of Semantics 27: pp. 1-35.

[56] Toledo, Assaf and Galit Sassoon. 2011. "Absolute vs. Relative Gradable Adjectives - Variance Withing vs. Between Individuals." Proceedings of SALT 21: pp. 135-154.

[57] Unger, Peter. 1975. Ignorance. Clarendon Press.

[58] Weatherson, Brian. 2012. "Knowledge, Bets, and Interests." In Knowledge Ascriptions. Edited by Jessica Brown and Mikkel Gerken. Oxford University Press.

[59] Wedgwood, Ralph. 2008. "Contextualism about Justified Belief." Philosophers Imprint 8: pp. 1-20.

[60] Wheeler, Samuel. 1972. "Attributives and Their Modifiers." Nous 6, no. 4: pp. 310-334.

[61] Yoon, Youngeun. 1996. "Total and Partial Predicates and the Weak and Strong Interpretations." Natural Language Semantics 4: pp. 217-236. 